Iara Sousa Castro ${ }^{1}$

Nedson Antônio Campos²

Ada Ávila Assunção ${ }^{3}$

Francisco de Paula Antunes Lima ${ }^{4}$

\title{
Diferenças interindividuais em teleatendi- mento de emergências: explicitação por meio da entrevista de autoconfrontação
}

\section{Inter-individual differences in emergency call center services: making them explicit by means of a self-confrontation interview}

\footnotetext{
${ }^{1}$ Escola de Design da Universidade do Estado de Minas Gerais (UEMG), Faculdade de Engenharia e Arquitetura da Fundação Mineira de Educação e Cultura (FUMEC), Belo Horizonte, Brasil.

${ }^{2}$ Departamento de Engenharia Elétrica e de Produção da Universidade Federal de Viçosa, Minas Gerais, Brasil.

${ }^{3}$ Departamento de Medicina Preventiva e Social - Faculdade de Medicina da Universidade Federal de Minas Gerais (UFMG), Belo Horizonte, Brasil.

${ }^{4}$ Departamento de Engenharia de Produção - Escola de Engenharia da Universidade Federal de Minas Gerais (UFMG), Belo Horizonte, Brasil.
}

\begin{abstract}
Resumo
O objetivo deste artigo é duplo. No âmbito teórico, apresenta a noção de modos operatórios singulares e diferenciados desenvolvidos no setor de teleatendimento; no âmbito metodológico, busca apresentar o valor da entrevista de autoconfrontação no estudo da atividade de trabalho. Inicialmente, são apresentados os métodos e os procedimentos utilizados para analisar a atividade em um serviço de atendimento às situações de emergências urbanas e, em seguida, é descrito o funcionamento do contexto produtivo estudado. Os trechos de diálogos de dez casos observados em situação foram autoconfrontados, permitindo aos autores a apresentação do desenrolar particular de cada atendimento dirigido pelo operador. Finalmente, discute-se a influência das diferenças interindividuais na atividade de teleatendimento e nos possíveis danos à saúde dos operadores.
\end{abstract}

Palavras-chaves: teleatendimento, emergência, entrevista de autoconfrontação, carga mental, diferenças interindividuais.

\begin{abstract}
This article is double aimed. At theoretical level, it introduces the idea of particular and distinguished operational modes; at methodological level, it presents the relevance of self-confrontation interviews when studying work practices. It starts introducing methods and procedures used to analyze an urban emergency call center practice; then, it describes how the specific production context under study operates. The dialogue fragments of ten observed subjects were self-confronted giving the authors the opportunity to present the singular development of each telemarketing service performed by each operator. Finally, the article discusses both the degree to which inter-individual differences influence telemarketing practices, and the possible damage caused to operators' health.
\end{abstract}

Keywords: call center, emergency, self-confrontation interview, mental load, inter-individual differences. 


\section{Introdução}

As dimensões cognitivas e afetivas da atividade são fatores reconhecidamente determinantes da carga de trabalho em situações de teleatendimento. Essas situações de trabalho são estudadas por diversas disciplinas, com seus métodos e conceitos específicos. Este artigo apresenta a entrevista de autoconfrontação, desenvolvida no campo da ergonomia, como técnica apropriada para compreender a atividade de trabalho dos teleatendentes.

A atividade de teleatendimento exige, a todo o momento, tomadas de decisões, criatividade, paciência, gentileza, experiência e competência para conduzir a conversa com o usuário e resolver o seu problema. Assim, o esforço mental, tanto cognitivo quanto afetivo, é permanente e a reação de cada atendente diante de cada situação depende de fatores ligados à experiência.

Se, por um lado, a implantação da informática favoreceu o setor de atendimento e seus trabalhadores, por outro lado, introduziu novas exigências: (1) aquelas derivadas da hipersolicitação das funções cognitivas mobilizadas no tratamento de uma multitude de informações na unidade de tempo, implicando em raciocínios rápidos, concentração, memória e atenção; (2) aquelas relacionadas ao atendimento ao público, o qual solicita amabilidade, paciência e cordialidade. Por exemplo, os estudos evidenciam os efeitos do uso de frases e expressões padronizadas as quais são incapazes de solucionar situações extremas apresentadas em serviços de emergências. A ausência de recursos para permitir compreender as demandas dos usuários agrava a tensão gerada no âmbito da atividade.

O esforço mental oriundo das situações citadas acima não é percebido da mesma maneira entre os teleatendentes. Embora eles alcancem resultados aparentemente semelhantes, o esforço de cada um para cumprir os objetivos da organização é particular a cada trabalhador. As diferenças da percepção da carga de trabalho revelam diferenças intra-individuais e interindividuais. As diferenças intra-individuais dizem respeito às variações do estado interno a cada um.

As diferenças interindividuais, foco deste artigo, estão relacionadas às características que diferem cada indivíduo do outro, como a história de vida, a bagagem cultural, a formação que confere habilida- de, a experiência, a destreza, a cordialidade, a criatividade, a capacidade de elaborar estratégias, enfim, tudo que influencia a maneira de cada indivíduo reagir às demandas do trabalho.

Embora os resultados alcançados no trabalho sejam, aparentemente, idênticos, os modos operatórios empregados mobilizam esforços e raciocínios diferenciados dependendo do indivíduo.

Alguns autores afirmam que a organização do trabalho no setor expõe os trabalhadores aos riscos de adoecimento, entre eles cita-se a forte pressão temporal como explicação para os ritmos acelerados dos operadores evidenciados durante toda a jornada de trabalho (ECHTERNACHT, 1998; SZNELWAR \& MASSETTI, 2000; BARRETO, 2001; TORRES, 2001). Além disso, pode não haver pausas ou intervalos suficientes entre os atendimentos para a recuperação das condições gerais do operador.

O controle do trabalho, instrumento capaz de garantir a eficiência, normalmente avaliada pelo tempo de atendimento, constitui-se característica marcante da atividade no setor (VILELA \& ASSUNÇÃO, 2004). Pode haver estímulos à competitividade entre colegas devido aos programas de produtividade calcados na individualização excessiva da produção. Registram-se também conflitos constantes com superiores hierárquicos e ausência de espaço organizacional para expressão, discussão e resolução de problemas.

A implantação de programas de Qualidade Total sofistica os métodos de monitoramento e avaliação do trabalho, expondo o desempenho dos atendentes e ao mesmo tempo gerando pressão contínua sobre a atividade. O avanço da tecnologia tem contribuído para melhorar a operação simultânea entre os softwares utilizados, reduzindo o tempo do atendimento e requerendo um aprendizado constante para a sua operação. Por outro lado, o sistema adota métodos que buscam a padronização e o controle da tarefa desempenhada pelo teleatendente. A gestão atual elabora métodos reducionistas da realidade do trabalho no setor, com perdas evidentes sobre a qualidade do atendimento. Os autores sinalizam os efeitos negativos das práticas de gestão, sendo citado o retrabalho e os seus efeitos estressantes sobre o trabalhador (MARX, 2000). 
As tecnologias provocam sessões de treinamento visando oferecer ao teleatendente possibilidade de conhecer as propriedades dos produtos ou serviços oferecidos pela empresa. Os treinamentos objetivam ainda: orientar os operadores sobre as formas de negociação cabíveis com o usuário, fornecer as técnicas de comunicação por telefone, técnicas de marketing e técnicas de relações públicas. Dos treinamentos fazem parte, também, as regras de utilização do sistema computadorizado, notando-se a relevância dos aspectos tecnológicos, haja vista a alteração que eles provocam sobre a atividade, uma vez que possibilitam o aumento da precisão e da velocidade na transmissão das informações e do papel do usuário como um consumidor exigente (TORRES, 2001).

Outro determinante da atividade do teleatendente refere-se ao componente físico da situação de trabalho, sobretudo às exigências de manutenção de posturas estáticas prolongadas para garantir o manejo dos dispositivos materiais do sistema (teclado,

\section{Métodos e procedimentos}

Inicialmente, são apresentados os métodos e os procedimentos utilizados para analisar a atividade dos teleatendentes e, em seguida, é descrito o funcionamento do contexto produtivo estudado. Na seqüência, através de trechos de diálogos ocorridos durante o atendimento de dez casos observados em situação e, posteriormente, autoconfrontados, será apresentado o desenrolar diferenciado dos atendimentos. Finalmente, discute-se a influência das diferenças interindividuais na atividade de teleatendimento e nos possíveis danos à saúde dos teleatendentes.

\section{Pressupostos metodológicos}

Recorrer à fala dos sujeitos para explorar as diferenças interindividuais é um procedimento adotado por todas as disciplinas que tomam o discurso como matéria-prima para analisar a subjetividade. A entrevista não-diretiva não assegura a manifestação autêntica da subjetividade. A não-diretividade comporta alguns vieses, dentre os quais cabe aqui ressaltar o reforço das diferenças sociais implícitas nas diferenças da capacidade de verbalização ou de expressão abstrata e conceitual que a técnica pode provocar (THIOLLENT, 1985). mouse, monitor). Geralmente, as exigências de posturas anômalas resultantes da configuração inadequada do ambiente e dos postos de trabalho somam-se aos efeitos das diferentes solicitações de processos cognitivos.

Os aspectos referidos acima podem estar presentes isolada ou simultaneamente em cada situação de trabalho e, filtrados pelas diferenças interindividuais, são percebidos por cada trabalhador em diferentes graus de intensidade. É interessante salientar que, além das diferenças entre teleatendentes, existem também as diferenças dos usuários, os quais possuem características próprias, envolvendo uma população eclética do ponto de vista social, financeiro e cultural.

O objetivo deste artigo é duplo. No âmbito teórico, apresenta a noção de modos operatórios singulares e diferenciados desenvolvidos no setor de teleatendimento; no âmbito metodológico, busca apresentar o valor da entrevista de autoconfrontação no estudo da atividade de trabalho.
A especificidade da análise ergonômica do trabalho e, particularmente, da entrevista em autoconfrontação está em convocar o sujeito trabalhador a expressar-se não sobre as "profundezas de sua alma" e de seus sentimentos, mas sim sobre a complexidade do seu comportamento atual. Não existe aqui nenhum julgamento de valor sobre a ordem de importância dessas instâncias, apenas um reconhecimento de diferença. Se adotada a abordagem psicologizante, o indivíduo é levado a mergulhar em seus próprios sentimentos e processos psíquicos, eventualmente em seus traumas psicofamiliares. Na contracorrente, o entendimento da ação em situação permite ao indivíduo revelar a trama complexa de seu comportamento diante das exigências do trabalho, resultante de diversas lógicas em jogo (às vezes, em conflito): do trabalhador, do coordenador, da chefia, do usuário, do sistema, da organização.

\section{Procedimentos de coleta e análise de da-} dos

Foi realizado um estudo ergonômico em um serviço de atendimento às emergências comunicadas pelos cidadãos por meio de telefonia, tendo como base os pressupostos da escola francesa (WISNER, 1987). 
Por meio de entrevistas abertas, buscou-se aproximação das dificuldades e conflitos encontrados na interface entre o teleatendente e o usuário. As primeiras etapas da pesquisa permitiram evidenciar os conflitos e os tempos indevidos para a realização dos atendimentos, haja vista a diversidade do seu conteúdo. A chefia e os coordenadores também foram entrevistados.

Inicialmente, os teleatendentes, que compunham seis equipes responsáveis pelo funcionamento do serviço durante 24 horas, foram observados e entrevistados. Os indivíduos observados foram escolhidos aleatoriamente por critério de livre adesão ao estudo. Assim, foram observados em situação de trabalho homens e mulheres, novatos e experientes, operadores de diversas faixas etárias, operadores terceirizados e vinculados à instituição, durante dias e horários diferentes. Nessa fase, as informações foram registradas sem triagem prévia. O objetivo foi entender o funcionamento do setor e as características gerais das tarefas. A escuta da verbalização operadorusuário foi restrita ao pólo teleatendente (operador). Em seguida, pesquisadores e observados expressavam verbalizações consecutivas sobre o conteúdo das verbalizações.

Diante dos limites da investigação, foi solicitada, com sucesso, a escuta direta e simultânea do diálogo travado entre os dois pólos. A nova etapa da pesquisa alcançou resultados profícuos, pois, além de ouvir a totalidade do diálogo, foi possível verificar como as coisas eram ditas. Podiase perceber o tom da voz, a dicção, o ruído da rua, a aflição do usuário, a desenvoltura do operador e o comportamento de ambos os pólos da comunicação.

A estratégia de coleta de dados viabilizou identificar as diferenças interindividuais e as diferenças das chamadas quanto ao conteúdo e ao volume, a depender dos horários e dias da semana. As análises provocaram a terceira etapa de coleta de dados, a qual foi dedicada a selecionar situações críticas, agudas e recorrentes tendo como referência dias e horários variados que caracterizavam situações peculiares.

A leitura dos dados colhidos revelou as situações recorrentes que foram apreendidas pelos pesquisadores e serviram para a elaboração das categorias para tratamento dos dados (Quadro 1).

A estrutura do texto é guiada pelos elementos-chave da atividade do teleatendente, que consiste em analisar detalhadamente a situação, procurando os traços que motivaram a chamada para, em seguida, decidir sobre a ocorrência (parte 1 dos resultados). No desenrolar de sua atividade, o teleatendente desenvolve competências, como se verá na parte 2 dos resultados.

\section{O processo de trabalho no teleatendimento de emergência}

O processo operacional inicia-se com a ligação do cidadão para o teleatendente, o qual, por sua vez, tem a função de caracterizar a solicitação recebida como sendo uma emergência ou não. Em caso positivo, ele gera a ocorrência, que é transmitida, via sistema, para o despachante, que, por sua vez, entra em contato via rádio com o coordenador das atividades operacionais. O coordenador é responsável pela fiscalização e auxílio dos trabalhos em uma determinada região geográfica. Após a definição, o coordenador retorna ao despachante, que entra em contato com o veículo de socorro,

Quadro 1 Componentes da atividade do teleatendente do serviço de emergência de uma metrópole

\footnotetext{
O teleatendente analisa detalhadamente a situação que motivou a ligação e decide sobre a ocorrência

O teleatendente esforça-se para resgatar da sua memória informações que julga importantes

O teleatendente esforça-se para auxiliar na decisão do usuário

O teleatendente preocupa-se em orientar o usuário

O teleatendente desenvolve competências através da experiência adquirida durante as situações enfrentadas

O teleatendente emprega técnicas sofisticadas

O teleatendente constrói parâmetros para identificar os tipos de chamadas

O teleatendente reconhece o trote

O teleatendente mobiliza estratégias comunicativas para tratar situações
} 
transmitindo as informações contidas no histórico da ocorrência, sempre via rádio.

Caso os agentes operacionais necessitem de informações adicionais, eles podem mobilizar o despachante, que poderá fornecê-las se estiverem disponíveis no sistema. Caso contrário, outros órgãos serão consultados pela coordenação.

Viu-se uma desproporção entre a oferta e a demanda de serviços via telefone, ainda que o serviço seja oferecido durante vinte e quatro horas por dia, durante todo o ano. O número de chamadas telefônicas varia, aproximadamente, entre $20 \mathrm{mil}$ e $50 \mathrm{mil}$ ligações diárias. Porém, dentre elas, apenas 10 mil são atendidas. Essas cifras são amostras referentes a uma média anual e a organização não consegue resolver o problema.

Dentre as chamadas que de fato são atendidas, $42 \%$ são trotes: crianças brincando na linha, pessoas que inventam estórias, que dizem palavrões ou que desligam quando ouvem a voz do teleatendente. Assim, a linha telefônica fica ocupada, impedindo que um cidadão, realmente necessitado, seja atendido.

A linha telefônica também fica ocupada de outras maneiras indevidas: $3 \%$ das chamadas atendidas são de pessoas da própria empresa que pedem, indevidamente, para o teleatendente transferir a ligação para outro ramal da empresa; $35 \%$ das chamadas atendidas são pedidos de informações e de orientações de diferentes naturezas, que não estão configuradas no serviço oferecido: serviço de auxílio à lista telefônica, serviço das fornecedoras de água e de energia, de prefeitura, de bombeiro, de hospitais, de departamento de trânsito, de questões jurídicas e também de questões relacionadas aos maus comportamentos e aos conflitos entre parentes ou pessoas conhecidas que necessitam de orientação.

Apenas 16\% das chamadas atendidas cumprem o objetivo do teleatendimento: registrar ocorrências de emergências e

\section{Resultados}

Como mencionado anteriormente, os teleatendentes enfrentam grandes dificuldades para extrair as informações necessárias para gerar uma ordem de serviço e, em seguida, cadastrá-las. Para conseguir identificar e entender as dificuldades e neces- encaminhar a ajuda necessária aos envolvidos. Apesar da discrepância, 44\% do tempo total empregado na atividade de teleatendimento destinam-se ao atendimento das ocorrências-alvo do sistema. Isso quer dizer que, apesar de reduzido o número de chamadas destinadas à geração de ocorrências, cerca de metade do tempo de atendimento é destinado às ocorrências-alvo.

Entretanto, os teleatendentes ocupam $47 \%$ do tempo fornecendo informações e orientações gerais. Estaria configurado o papel de assistente social do teleatendente, o qual se sente responsável pela situação do outro que efetua a ligação? Por exemplo, existem pessoas que ligam para dizer que estão no alto de um edifício e que pretendem se suicidar. Viu-se o teleatendente não conseguir se omitir e conversar com a pessoa até sentir que ela recuaria na sua decisão.

O restante do tempo de trabalho analisado foi empregado em distintas operações e objetivos: $3 \%$ destinados às transferências de ligações para outros setores da empresa e $6 \%$ destinados aos trotes. Assim, embora o trote seja o tipo de ligação atípica com maior incidência, o tempo dispendido não é significativo quanto à ocupação da linha telefônica. Entretanto, trata-se de uma chamada geradora de sobrecarga emocional para os teleatendentes que, dependendo do contexto, manifestam irritação.

Em muitos casos, a prestação do serviço é considerada tardia e lenta, pois contam com poucos recursos técnicos e humanos para atender imediatamente a todos os casos da cidade. Os teleatendentes priorizam os casos mais graves ou os casos com margens para intervenção do serviço.

As entrevistas em autoconfrontação fizeram emergir as dificuldades enfrentadas pelos teleatendentes e o esforço mental mobilizado para realizar sua atividade de trabalho. Vários trechos de diálogos serão apresentados a seguir. sidades dos teleatendentes, foi necessário conhecer a sua atividade de trabalho.

Os trechos de diálogos de dez situações analisadas, oriundos das entrevistas de autoconfrontação e apresentados a seguir, colocam em evidência elementos esclare- 
cedores do esforço cognitivo no tratamento das situações, as variações interindividuais diante de cada situação e a necessidade de uma experiência prévia como atendente de rua para exercer a atividade.

O teleatendente analisa detalhadamente a situação que motivou a ligação e decide sobre a ocorrência

\section{Caso 1}

$\mathrm{O}$ atendente esforça-se em caracterizar a situação apresentada pela usuária para, em seguida, se for o caso, dar-lhe as devidas orientações visando acalmar e/ou orientar a cidadã (Quadro 2).

O exemplo citado ilustra o comportamento freqüente do teleatendente em esclarecer à usuária a inadequação da demanda aos objetivos do sistema, mas sem perder de vista o objetivo de satisfazer a usuária em sua necessidade primária. Viu-se o teleatendente tentar, novamente, orientá-la sobre a conduta visando à certificação do sumiço do marido. A intenção do teleatendente é orientá-la a procurar mais detalhes da situação, para, em seguida, entrar em contato com a prestação de serviços em tela, visando cadastrar o desaparecimento do marido. Sendo freqüente esse tipo de demanda dos usuários, os teleatendentes procuram filtrar as solicitações consideradas precipitadas.

$\mathrm{O}$ atendimento durou cerca de nove minutos e vinte segundos, sendo dois terços do tempo empregado com as orientações à usuária. Por fim, ele toma decisão de ca-

Quadro 2 Teleatendente se esforça para orientar o cidadão (caso 1)

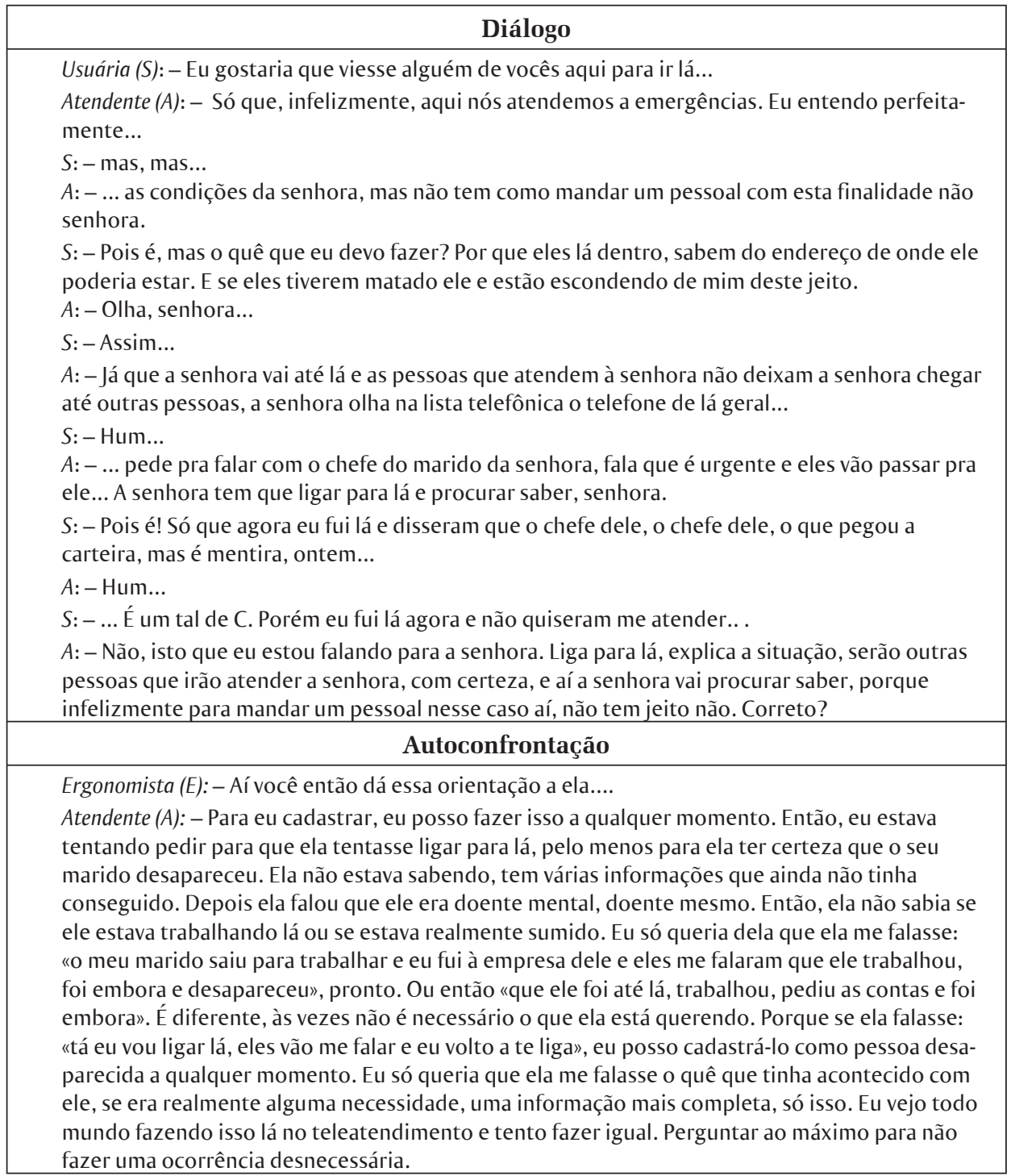


dastrar a pessoa como desaparecida. Os elementos da análise efetuada permitem indagar sobre o tempo utilizado por outro atendente no tratamento de questão semelhante.

\section{Caso 2}

Não é incomum o usuário estar emocionalmente perturbado, exigindo do teleatendente habilidade para controlar o comportamento do usuário e ajudá-lo na expressão do seu problema.

O caso seguinte diz respeito ao desaparecimento de pessoa com idade avançada e problemas mentais. No extrato reproduzido abaixo, o teleatendente está preenchendo o campo referente ao histórico do fato. Ele relembra o comentário da usuária anterior sobre o estado mental do seu marido e elabora uma pergunta para obter dados a registrar no campo referente ao histórico do caso. A habilidade requerida revela a perspicácia do teleatendente novato e evidencia outro elemento: os limites do treinamento teórico. É razoável perguntar: o treinamento tradicional contempla as competências desenvolvidas pelo teleatendente em sua experiência pregressa em atividade de operador de rua?

\section{Caso 3}

Para diminuir o esforço cognitivo provocado pela incompatibilidade entre a cronologia dos fatos narrados pelo usuário e a lógica do sistema que apresenta uma ordem de preenchimento dos campos, os teleatendentes utilizam-se, à vezes, de um pedaço de papel para anotar os dados do fato gerador da ocorrência que devem ser inseridos no histórico. A Figura 1 ilustra as anotações do teleatendente. Os dados con-

Quadro 3 Teleatendente esforça-se em resgatar da sua memória informações consideradas importantes (caso 2)

\begin{tabular}{|l|}
\hline \multicolumn{1}{c|}{ Diálogo } \\
\hline Atendente (A): - Ele apresenta algum problema mental, senhora? \\
Usuária (S): - Sim, ele apresenta sim. Porque ele só fica com a mão num lado do rosto, né? E fica \\
juntando uns pauzinhos de lenha e assentado, se deixar, ele fica o dia inteirinho assentado no \\
mato... Por isto que eu estou te falando que eu estou com medo de ter acontecido alguma coisa \\
com ele na firma ou qualquer coisa... \\
\hline \multicolumn{1}{c|}{ Autoconfrontação } \\
\hline Atendente (A): - Como ela já tinha falado, eu só confirmei com ela: ele tem problemas mentais, \\
correto? Ela: tem. \\
Ergonomista (E): - Isso aí você anotou no histórico? \\
A: - Coloquei no histórico. A gente apresenta problemas mentais, distúrbios mentais. \\
E: - Para você lembrar você tinha anotado em um papel? \\
A:- Não, não. Lembrei mesmo. \\
E: - Então, vocês têm que tá memorizando... \\
A: - É porque, num sei, a gente... tocou o telefone você tem que estar atento em tudo, né, que \\
ela tá falando.
\end{tabular}

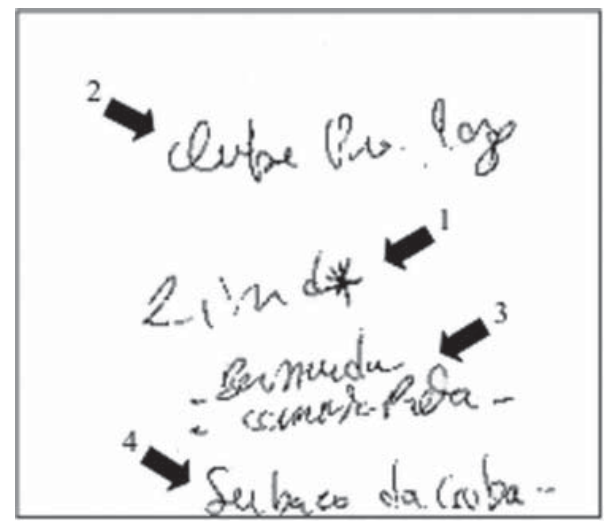

Figura 1 Anotação feita por um dos teleatendentes durante seu trabalho. A seta 1 indica "2 indivíduos", que é o número de pessoas envolvidas no fato; a seta 2 indica "Clube do Lazer", que é a referência; a seta 3 indica "bermuda, camisa preta", a descrição dos suspeitos, e a seta 4 indica "Sovaco de Cobra", o nome do local do fato gerador de ocorrência. 
tidos no papel são aqueles utilizados para redigir uma ocorrência.

Em certos casos, o atendente se esforça para não reagir emocionalmente às agressões do usuário, que pode estar completamente atônito, sem clareza de raciocínio, dirigindo as suas questões de forma agressiva.

Em suma, os resultados das observações deixam claro que o teleatendente se esforça para auxiliar o usuário a decidir sobre a ocorrência levando em consideração que, em meio a uma situação tensa, o indivíduo tem menos chances de tomar a decisão que ele mesmo julgaria ser a melhor em um outro momento. Mas quando não considera necessário gerar a ocorrência, o atendente oferece ao usuário a possibilidade de decidir em outro momento de mais calma (Quadro 4).

A qualidade desta prestação de serviço possibilita deixar em aberto o desfecho da interação entre o usuário e o atendente quando, em princípio, deveria ser o teleatendente a tomar a decisão final. Neste caso, o atendimento durou cerca de dez minutos. Foi um tempo relativamente parecido com o caso 2, entretanto, empregou apenas um minuto e trinta segundos para começar a gerar a ocorrência. O restante do tempo foi utilizado para extrair as informações do usuário e inseri-las no sistema. É razoável supor que a maior duração do tempo para cadastramento dos dados seria conseqüência do modo operatório do teleatendente experiente e, por isso, mais cuidadoso na elaboração das perguntas ao usuário. O número maior de informações cadastradas denota um atendimento mais qualificado e diferenciado.

\section{Caso 4}

Viu-se o teleatendente orientar uma usuária em assuntos aparentemente banais, mas de extrema valia para ela. A população não é informada sobre os reais objetivos deste serviço de emergência, gerando solicitações imprudentes. Diante dessas situações, o teleatendente esforça-se para orientar a usuária a se dirigir a outros serviços ou então para explicar como funciona a prestação do serviço de emergência, como mostra o Quadro 5.

\section{Caso 5}

$\mathrm{O}$ atendente tem a preocupação com a classificação das solicitações que recebe em relação à prioridade de atendimento. $\mathrm{Na}$ hierarquia de prioridades, estariam os casos passíveis de intervenção, para os quais valeria a pena o deslocamento da equipe até o foco desencadeador do registro no sistema. O Quadro 6 ilustra essa afirmação.

A prioridade não é definida apenas pelo sistema que registra o tempo do evento. A competência do atendente também é determinante no estabelecimento da prioridade, sendo necessário considerar a natureza precisa da ocorrência.

\section{O teleatendente desenvolve competências}

\section{Caso 6}

Os teleatendentes desenvolvem estratégias comunicativas para tratar situações. No extrato do quadro 7, a usuária, após afirmar a cor do seu marido, não consegue afirmar a cor do seu cabelo. O teleatendente, com a intenção de acelerar a resposta da usuária, imagina que provavelmente a cor do cabelo de uma pessoa morena seria castanha ou preta e pergunta para confirmar a

Quadro 4 Teleatendente se esforça para auxiliar na decisão do usuário (caso 3)

\begin{tabular}{|l|}
\hline \multicolumn{1}{|c|}{ Diálogo } \\
\hline Atendente $(A):-$ O senhor já fez ocorrência de pessoa desaparecida? \\
Usuário (S): - Não \\
(A): - O senhor deseja fazer? \\
(S): - Eu vou procurar o Departamento de Investigação então, né? \\
(A): - Não dá para fazer verbalmente. Depois você procura o Departamento de Investigações. \\
(S): - Ah, tá. \\
(A): - Qual é o nome dele? \\
\hline Autoconfrontação \\
\hline $\begin{array}{l}\text { Atendente (A): - A gente deixa a opção. Talvez possa ser um familiar que frequientemente cos- } \\
\text { tuma desaparecer. Ou ele tem seus problemas de bebida, entendeu? Enfim, todos os proble- } \\
\text { mas, né? Então a gente deixa a opção: se deseja fazer ou não a ocorrência. }\end{array}$ \\
\hline
\end{tabular}


Quadro 5 Teleatendente preocupa-se em orientar o usuário (caso 4)

\begin{tabular}{|l|}
\multicolumn{1}{c|}{ Diálogo } \\
\hline Atendente (A): - A minha senhora. O quê que está ocorrendo aí? \\
Usuária (S): - Hã? Não. É o seguinte: porque dois adolescentes, ontem à noite, tiveram uma \\
discussão em casa e os dois nunca fizeram isso. Eles pegaram até faca um para o outro. Então, \\
eu queria que viesse, se fosse possível, um policial ou alguém que conversasse com eles, porque \\
é a primeira vez que acontece, né? Quê se eu deixar, depois pode acontecer coisa pior. \\
A:- Tá, mas deixa eu falar com a senhora. O problema deles, a agressão deles foi ontem, correto? \\
S:- Ah, ontem à noite. \\
A:- Por que que ontem à noite, a senhora ou alguém da família não ligou para cá? \\
S:- Porque um saiu, um saiu e quando ele retornou, já era 1:30h da manhã. Então eu fiquei que, \\
achei que, por ter ido ao quartel de manhã, viria alguém aqui, mas ninguém apareceu. Daqui a \\
pouco eles saem para o colégio. \\
\hline Autoconfrontação \\
Ergonomista (E): - Por que você fez essa pergunta para ela? \\
Atendente (A): - Porque preciso saber se é uma coisa que requer uma intervenção imediata do \\
nosso serviço, correto? Ela me passando um quadro da situação, que se fosse alguma coisa \\
imediata, a providência seria tomada daqui, né? \\
E:- Nesta estória você destaca que foi ontem, né? Por que que você faz isso? \\
A:-É. Porque pra gente aqui é importante saber que tempo que ocorreu o fato, né? Porque pra \\
gente, se foi alguma coisa de imediato é com a gente mesmo que resolve. Caso se for alguma \\
coisa já passada, a pessoa tem que procurar diretamente uma delegacia de polícia civil para \\
fazer a representação lá. \\
E:- E aí você pergunta porque que você não ligou ontem? \\
A:- Exatamente, sendo que oferecemos um serviço aqui de 24 horas, né? Então qualquer pes- \\
soa que nos comunicar o fato, nós vamos anotar e tomar providência. \\
\hline
\end{tabular}

Quadro 6 O teleatendente preocupa-se com a prioridade entre as solicitações (caso 5)

\begin{tabular}{l} 
Diálogo \\
\hline Atendente (A): - Emergência (...) Veto. \\
Usuário (S): - Boa Tarde. Eu gostaria de fazer uma ocorrência. Estou aqui em um posto da \\
Engenharia onde trabalho, no Carlos Prates, perto do aeroporto. É, houve um roubo de uns \\
pranchões aqui. Uns malandros roubaram os pranchões e ameaçaram voltar. Gostaria de fazer \\
uma ocorrência para resguardar a empresa. \\
Atendente: - Furtaram agora? \\
Usuário: - Tem mais ou menos vinte a trinta minutos. \\
\hline \multicolumn{1}{c|}{ Autoconfrontação } \\
Ergonomista (E): - Parece que houve uma preocupação com o tempo, né? Se foi agora, né? Por \\
que esta pergunta de imediato? \\
Atendente (A): - Porque imagina que o funcionário deixa passar muito tempo de quando ocorreu \\
o evento e só quando o chefe cobra dele que ele vai ligar para registrar. Se for só isso, não há ne- \\
cessidade de prestar o serviço imediatamente. Este chamado vai ter menos prioridade no envio \\
do carro de socorro. Mas te tiver sido agora, neste exato momento, aí a gente manda o socorro \\
para tentar pegar o delinquiente. O objetivo principal é pegar e não só fazer o registro. Se foi \\
agora, aí há mais expectativa de pegar os bandidos. Se já passou muito tempo, aí é só o registro. \\
E:- E esse tempo. Ele fala vinte a trinta minutos. Isto é muito ou pouco. Isto é um socorro \\
imediato ou não? \\
A:- Trinta minutos é muito. Demorou muito tempo para ligar. \\
E: - E você colocou como emergência ou não. \\
A: - Existe prioridade de 1 a 4 . Neste caso, o próprio sistema o colocou como 3 na classificação \\
de prioridade. Por causa do tempo, depois de vinte minutos a gente não pega mais nada. \\
A: - A gente muda a prioridade para cada caso. Às vezes, numa ocorrência de apenas cinco \\
minutos, existe a possibilidade de pegar o camarada, mas ao mesmo tempo tem outra ocorrên- \\
cia de assalto à mão armada. Esta é principal sobre a outra porque corre risco de vida. A vítima \\
corre risco de vida no assalto à mão armada e no furto não. No furto, o cara não está armado e \\
não houve força para tomar da pessoa, entendeu? \\
\hline
\end{tabular}


sua suposição. A intervenção do teleatendente justifica-se pelo objetivo de encurtar os tempos para poder atender mais pessoas, conforme ele relata (Quadro 7).

\section{Caso 7}

Os teleatendentes praticam uma análise do conteúdo da entrevista do cidadão uti- lizando-se de técnicas sofisticadas, como repetir o que foi falado pelos usuários no final do seu discurso, saber mais detalhes e ouvir um pouco mais sobre o que está sendo falado.

O fato de o usuário pedir apenas o telefone, associado ao tom de voz que não expressava desespero, permitiu ao atendente

Quadro 7 Teleatendente mobiliza estratégias comunicativas para tratar situações (caso 6)

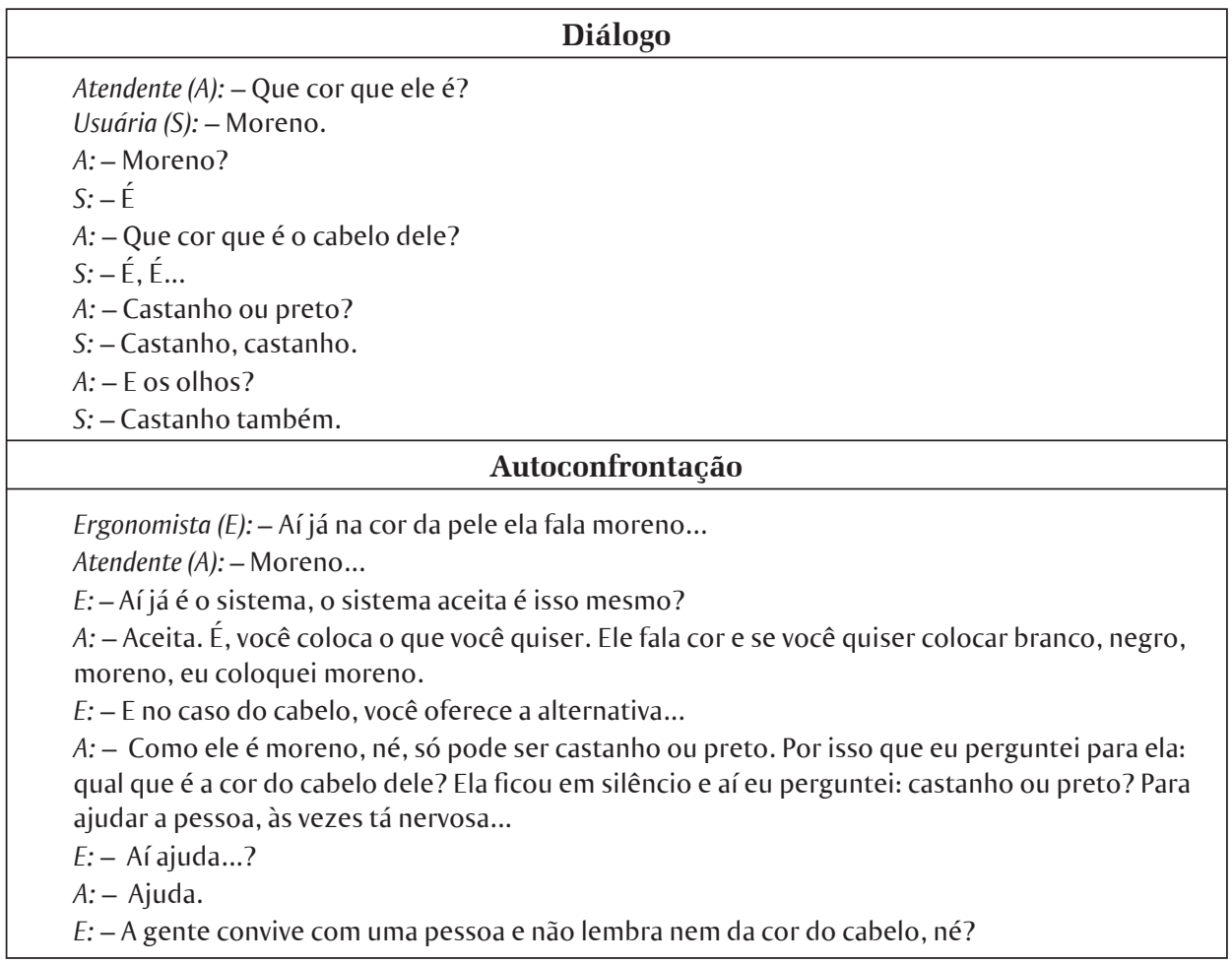

Quadro 8 O teleatendente emprega técnicas sofisticadas para saber detalhes (caso 7)

\begin{tabular}{|l|}
\hline \multicolumn{1}{c|}{ Diálogo } \\
\hline Atendente (A): - Emergência... \\
Usuário (S): (sussurro ininteligível) \\
A: - Alô! \\
S: - Alô, deixa eu te falar. Eu quis... qual é o telefone... \\
A: - Hein? \\
S: - Sabe, o telefone da FEBEM. \\
A: - Não informamos telefone não. Ok? \\
S: - Porque eu tinha ligado por causa que o meu pai e a minha mãe tão me maltratando. Aí, eu \\
só queria saber o telefone da FEBEM. \\
A: - Não. Nós não informamos, ok? \\
S: - Então tá. \\
\hline \\
Ergonomista (E): - Mesmo com esse argumento de que estava sendo maltratada, você consegue \\
perceber que não era um caso de mandar socorro? \\
Atendente (A): - Quando o socorro chegasse, não teria como constatar porque teria que fazer \\
contato com os pais que iriam negar. Por outro lado, o usuário pediu o telefone. É bem dife- \\
rente da pessoa falar o seguinte: “olha, eu estou precisando de socorro aqui porque eu estou \\
sendo agredida”. É bem diferente, ela pediu o telefone. \\
\hline
\end{tabular}


descartar o caráter de emergência da situação (Quadro 8).

\section{Caso 8}

Os teleatendentes constroem parâmetros para identificar os tipos de chamadas. Como dito anteriormente, o trote é comum, ou seja, ligações de pessoas que inventam uma estória para parecer que precisam do atendimento de socorro. Os atendentes, ao longo do tempo, desenvolvem e refinam as habilidades que permitem criar e desenvolver certas estratégias para identificar um trote. Não existe receita, mas o diálogo com o usuário provoca a evidência da mentira em certos momentos, como ilustra o diálogo descrito no Quadro 9.

Para evitar equívocos de enviar socorro em situações desnecessárias, tentam certificar-se do endereço e se o informante aguardará a chegada do socorro. Caso contrário, o socorro não é enviado.

\section{Caso 9}

Quando o atendente mostra preocupação em reconhecer um trote, revela competência desenvolvida e a ética com o seu trabalho, como mostram os diálogos reproduzidos nos Quadros 10 e 11.

Quadro 9 O teleatendente constrói parâmetros para identificar os tipos de chamadas (caso 8)

\begin{tabular}{|l|}
\hline \multicolumn{1}{|c|}{ Diálogo } \\
\hline Atendente (A): - Tá. Por favor, como é que é o nome do senhor? \\
Usuário (S): - Fábio Augusto \\
A:- De quê? \\
S: - Dos Santos \\
A: - O senhor trabalha aí? \\
S:-É, trabalho. Eu faço a vigilância aqui no local. \\
\hline \multicolumn{1}{c|}{ Autoconfrontação } \\
\hline Ergonomista (E): - Você perguntou se ele trabalha lá... \\
Atendente (A): - Às vezes a gente faz uma pergunta no meio da entrevista para saber se não é trote, \\
entendeu? Você entrevista a pessoa para ver se ela não vai planejar, se ela está de molecagem. \\
E:- E nesse caso, por acaso você suspeitou que fosse? \\
A:- Não, pela firmeza dele, apesar de que tem cara artista. Uma vez eu gerei uma ocorrência \\
de assalto na porta do quartel na praça da rua Alvarenga Peixoto, num posto de gasolina. Era \\
noite, o cara ligou e deu até as características das pessoas. O socorro chegou lá em menos de \\
cinco minutos e não era nada. Conversaram com o frentista e ele disse que não houve assalto \\
nenhum. O pessoal olhou lá dentro do posto, pois de repente o bandido podia estar vestido de \\
frentista e está armado, mas não era nada. Era um trote. \\
\hline
\end{tabular}

Quadro 10 O teleatendente reconhece o trote (caso 9)

\begin{tabular}{|c|}
\hline Diálogo \\
\hline $\begin{array}{l}\text { Atendente (A): - Emergência... } \\
\text { Usuário (S): - Socorro! Tem um ladrão roubando minha casa aqui. Socorro! Rua X, número } 75 . \\
\text { Por favor moço... } \\
\text { A: - Alô! } \\
\text { S: - Por favor! } \\
\text { A: - Alô! } \\
\text { S: - Por favor! } \\
\text { A: - Alô! } \\
\text { S: - t.n.c. (um palavrão), sô! } \\
\text { A: (Desliga) - O que mais aparece é trote! }\end{array}$ \\
\hline Autoconfrontação \\
\hline $\begin{array}{l}\text { Ergonomista (E): - Você falou "alô" e aí ele falou "por favor" várias vezes. Parece que você está } \\
\text { tentando ouvir o que está acontecendo no ambiente, até que ele fala um palavrão. } \\
\text { Atendente (A): - Isso! Ele falou um xingamento mesmo. Aí eu detonei. Vi que era um trote de } \\
\text { criança. } \\
\text { E: - Aí detona. } \\
\text { A: - Isso! } \\
\text { E: - Mas aí, esses espaços todos, esses alôs que você foi falando... } \\
\text { A:-É a gente procura buscar porque às vezes pode ser verdade. No meu caso, por exemplo, } \\
\text { quero evitar de amanhã ser surpreendido com um noticiário por um mal-entendido aqui. }\end{array}$ \\
\hline
\end{tabular}


Quadro 11 O teleatendente reconhece o trote (caso 9)

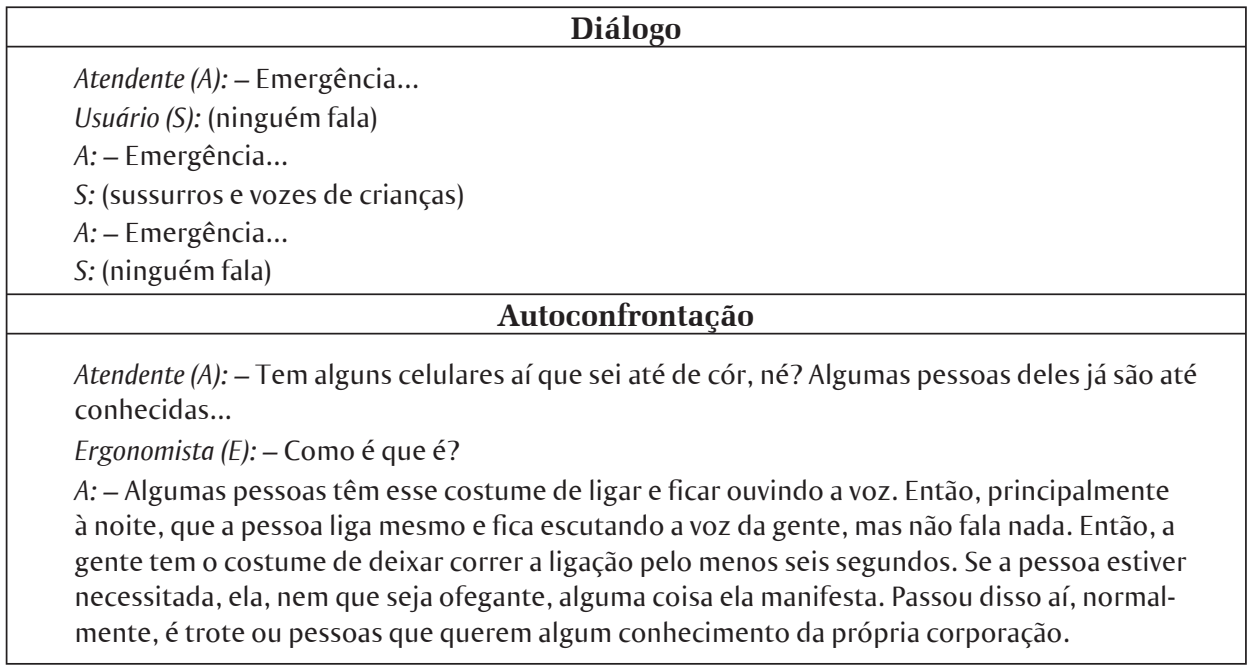

\section{Caso 10}

Outro ingrediente da competência do teleatendente é a capacidade de reconhecer e lidar com usuários contumazes do serviço de emergência. Eles são capazes de re-

\section{Discussão}

Um dos principais aspectos das diferenças interindividuais que a entrevista de autoconfrontação permitiu conhecer foi a importância da experiência do teleatendente para executar o seu ofício. Entende-se por experiência o tempo que passa ou passou desempenhando uma tarefa, o que permite à pessoa que trabalha apreender os mecanismos próprios de uma determinada atividade. Contudo, a experiência é algo mais do que simplesmente compreender, praticar e automatizar tarefas.

À medida que o trabalhador vive a situação de trabalho, ele reage a ela em uma interação em que a atividade é alvo constante de aperfeiçoamento e é adaptada, na medida do possível, em função de melhorias requeridas, sejam elas da produção, para corrigir imperfeições do sistema formal ou para a proteção da saúde.

Os trechos de diálogos apresentados evidenciaram a dificuldade dos teleatendentes em extrair as informações do usuário que não consegue responder de forma objetiva às perguntas. O usuário pode ficar aflito para informar sobre o seu problema e, ainda, não conhecer a lógica dos procedimentos do atendimento e, também, não discernir a informação relevante para acionar conhecer a voz de um usuário reincidente e números de telefones já conhecidos que aparecem na bina com freqüência e, conseqüentemente, não prosseguem o registro da ocorrência. o sistema. Nesse contexto, viu-se gerar uma certa impaciência em ambas as partes: o usuário pensa que o teleatendente não está querendo ouvi-lo ou pergunta desnecessariamente e, por outro lado, o teleatendente pensa que o usuário não está colaborando para a resolução do seu problema (MASCIA \& SZNELWAR, 2000).

Outro determinante para os mecanismos de adaptação utilizados pelo operador para lidar com a situação real de trabalho é a característica de variabilidade que ela contém. Em função dessa variabilidade, o trabalhador reage ao contexto - que é diverso a cada momento -, o que proporciona situações singulares que vão contribuindo para a construção do todo a que nos referimos como "experiência".

Assim, a atividade de trabalho desenvolve-se em uma situação na qual é difícil não só a previsibilidade como a prescrição. A complexidade das combinações entre situações previstas e imprevistas se torna causa da dificuldade enfrentada e a descrição antecipada da atividade é também dificultada, pois aparece a diferença entre o que se prescreve e o que se faz. Essa diferença é vista normalmente como um descumprimento da norma e serve como parâmetro para ava- 
liar (de forma negativa) o desempenho do trabalhador quando ele foge ao prescrito. Porém, a atividade real é, na verdade, no nosso entendimento, a forma como ele (o trabalhador) busca o melhor meio de desempenhar o seu trabalho, criando alternativas mais eficazes para agilizar o processo e, muitas vezes, preservar sua saúde.

As entrevistas de autoconfrontação mostraram-se eficientes para elucidar as dificuldades dos trabalhadores para desempenhar sua atividade, as inadequações dos meios de trabalho, as insatisfações dos usuários, os conflitos interpessoais e os fatores que influenciam negativamente a qualidade do serviço prestado.

Por meio delas, também foi possível perceber uma angústia do teleatendente no seio da seguinte contradição: oferecer um serviço de qualidade à população, garantindo que todas as chamadas sejam atendidas sem espera, e oferecer qualidade no serviço prestado, independentemente da operação necessária entrar em conflito com as regras formais da empresa.

As habilidades, os conhecimentos e o estado emocional do usuário que requisita um serviço influenciam fortemente o trabalho do teleatendente. Comumente, o usuário está aflito, pois as situações que motivam uma solicitação a esse serviço de emergência são urgentes, podem ser violentas e envolver risco de vida.

O estado emocional também contribui para a pouca nitidez da solicitação. Nessas situações de dificuldades em se expressar, o teleatendente necessita de tempo e habilidade para contornar a situação, mobilizando estratégias finas para obter as informações necessárias.

O teor emocional do usuário pode afetar, também, o estado emocional do teleaten-

\section{Considerações finais}

Viu-se a riqueza da técnica da autoconfronatação diante da possibilidade de recuperar a memória do teleatendente, o qual pôde expressar os caminhos de seu raciocínio até a tomada de decisão: encerrar a chamada, desencadear o dispositivo ou continuar escutando para confortar o cidadão desesperado, mas para o qual o serviço não teria, em tese, uma indicação do que fazer.

As análises dos dados coletados deixaram pontos incompreendidos. Para apro- dente. Essa condição pode ser prejudicial, considerando-se a objetividade que o teleatendimento deve ter. $\mathrm{O}$ não envolvimento emocional significa que o teleatendente deve ser imparcial com a situação, evitando pronunciar sua opinião sobre o evento relatado pelo usuário. No entanto, como foi evidenciado nas autoconfrontações, o atendimento é conduzido por julgamentos e avaliações que definem o encaminhamento final. Faz parte do esquema de ação do teleatendente reconhecer as prioridades, avaliar, por exemplo, se o caso exigiria o envio imediato de um carro de socorro. Os teleatendentes afirmam que o objetivo não é registrar a ocorrência, mas permitir a ação de socorrer o chamado. Uma lista de prioridades não seria suficiente para o teleatendente tomar a decisão, pois os eventos se cruzam e o teleatendente tem que combinar parâmetros antes de tomar a decisão, o que configura uma situação complexa de trabalho.

A complexidade da atividade está diretamente ligada ao esforço mental ao qual o teleatendente é exposto e que pode lhe causar danos à saúde. No caso deste estudo, havia queixas relacionadas ao estresse, à fadiga e à tensão desencadeados pela própria natureza da tarefa, pela auto-exigência de realizar um bom serviço e pelo mau uso feito pela população ao solicitar serviços que não diziam respeito aos propósitos da corporação.

Sendo assim, se for comparado o desempenho e a agilidade de um teleatendente novato aos de um teleatendente que já teve muita experiência em prestar serviços como operador de rua, fica evidente a importância da experiência na tomada de decisões rápidas e com mais segurança sobre como extrair informações e quais informações são fundamentais para auxiliar o trabalho do operador de rua.

fundar o diagnóstico, a técnica da autoconfrontação revelou-se útil e adequada aos objetivos traçados. Para esse efeito, adotouse a gravação dos atendimentos e posterior degravação e, finalmente, a confrontação do material coletado.

O emprego da autoconfrontação cruzada (quando um trabalhador comenta sobre a descrição da atividade de um colega - CLOT, 1999) poderia elucidar alguns pontos que ainda permanecem em aberto 
quanto ao significado das diferenças observadas. Assim, consegue-se, pela observação do comportamento de um outro, fazer com que o trabalhador explicite e reflita sobre sua própria maneira de lidar com as exigências do trabalho.

A priorização dos casos é feita sob critérios construídos com a experiência em situações de operações na rua. Baseando-

\section{Referências bibliográficas}

BARRETO, F. O sofrimento psíquico e o processo de produção no setor de telefonia: tentativa de compreensão de uma atividade com caráter patogênico. 2001. Dissertação (Mestrado em Engenharia de Produção) Escola de Engenharia, Universidade Federal de Minas Gerais, Belo Horizonte, 2001.

CLOT, Y. La fonction psychologique du travail. Paris: PUF, 1999.

ECHTERNACHT, E. A produção social das lesões por esforços repetitivos no atual contexto da reestruturação produtiva brasileira. 1998. Tese (Doutorado em Engenharia de Produção) - COPPE, Universidade Federal do Rio de Janeiro, Rio de Janeiro, 1998.

MARX, R. LER e organização do trabalho no setor de serviços: o caso de call centers em atendimento de serviços financeiros. In: SZNELWAR, L.; ZIDAN, L. (orgs). O trabalho humano com sistemas informatizados no setor de serviços. São Paulo: Plêiade, 2000. p. 81-86.

MASCIA, F.; SZNELWAR, L. Diálogo e constrangimentos do script na atividade de atendimento a clientes. In: SZNELWAR, L.; ZIDAN, L. (orgs). O trabalho humano com se em experiências passadas, o operador consegue avaliar as necessidades e as dificuldades que os agentes de rua enfrentarão, bem como as possibilidades de êxito na realização do atendimento. Assim, para garantir uma melhor qualidade do atendimento, também é necessário o teleatendente ter vivenciado todas as etapas do processo, característica incomum no efetivo estudado.

sistemas informatizados no setor de serviÇOS. São Paulo: Plêiade, 2000. p. 97-104.

SZNELWAR, L.; MASSETTI, M. Sofrimento no trabalho: uma leitura a partir de grupos de expressão. In: SZNELWAR, L.; ZIDAN, L. (orgs) O trabalho humano com sistemas informatizados no setor de serviços. São Paulo: Plêiade, 2000. p. 105-117.

THIOLLENT, M. Crítica metodológica, investigação social e enquête operária. 4 ed. São Paulo: Polis, 1985.

TORRES, C. A atividade nas centrais de atendimento: outra realidade, as mesmas queixas. 2001. Dissertação (Mestrado em Psicologia), Universidade de Brasília. Brasília, 2001.

VILELA, L. V. O.; ASSUNÇÃO, A. A. Os mecanismos de controle da atividade no setor de teleatendimento e as queixas de cansaço e esgotamento dos trabalhadores. Cad. Saúde Pública, v. 20, n. 4, p. 10691078, 2004.

WISNER, A.por dentro do trabalho: ergonomia: método e técnica. São Paulo: FTD, Oboré, 1987. 